\title{
Effect of Educational Workshops on Disaster Risk Perception in Nurses
}

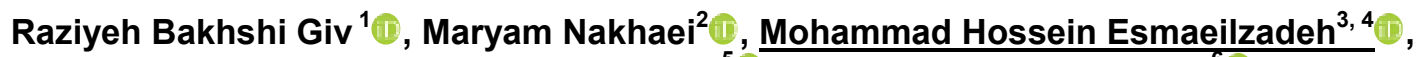 \\ Seyed Mohammad Reza Hosseini ${ }^{5}$, , Gholam Reza Sharifzadeh ${ }^{6}$
}

Date of submission: 22 Aug. 2020 Date of acceptance: 31 Oct. 2020

\section{Original Article}

Abstract

INTRODUCTION: The enhancement of nurses' risk perception plays a significant role in their preparedness during disasters and emergencies. Therefore, this study aimed to investigate the effect of educational workshops on disaster risk perception in nurses.

METHODS: This randomized controlled field trial study included 62 nurses working at Razi Hospital, Birjand, Iran. The participants were divided into intervention and control groups. The intervention group was then requested to participate in a one-day intensive educational workshop based on the current national standards. The workshop content included a combination of lecturing methods, round-table exercises, and film display. The data were collected using the demographic characteristic form and researcher-made questionnaires measuring the nurses' risk perception during disasters and emergencies. Subsequently, the data were analyzed using independent t-test, repeated measures analysis, and Bonferroni post hoc tests.

FINDINGS: The mean total score of risk perception were significantly higher in the intervention group before, immediately, and two months after the workshop session, compared to those in the control group $(\mathrm{P}<0.001)$.

CONCLUSION: The implementation of nurses' national preparation program during disasters and emergencies can result in an increase in the nurses' risk perception during these events. Therefore, regarding the importance of nurses' preparedness in confrontation with disasters and emergencies, it seems necessary to integrate the National Preparedness Program into the educational programs immediately after recruitment and in the form of in-service courses.

Keywords: Disasters; Emergencies; Hospitals; Preparation; Risk Appraisal.

How to cite this article: Bakhshi Giv R, Nakhaei M, Esmaeilzadeh MH, Hosseini SMR, Sharifzadeh GR. Effect of Educational Workshops on Disaster Risk Perception in Nurses. Sci J Rescue Relief 2020; 12(4): 270-78.

\section{Introduction}

$\mathrm{T}$ Today, the consequences of natural and manmade disasters, including body losses and financial damages, have an indisputable impact on the provision of essential needs resulting in a large number of deaths, injuries, and disabilities worldwide (1). According to the Emergency Events Database, at least 396 natural disasters occurred in 2019 that led to the death of 11,755 people. Moreover, it affected 95 million other people and caused 130 million dollar economic damages. Since $40 \%$ of natural disasters occur in Asia, it is regarded as the most vulnerable continent that involves $45 \%$ of the total life tolls and $74 \%$ of all people that were affected by natural disasters. The low- and

\footnotetext{
1- MSc, Emergency Nursing, Department of Nursing, Nursing and Midwifery School, Birjand University of Medical Sciences, Birjand, Iran

2- PhD, Nursing and Midwifery School, Birjand University of Medical Sciences, Birjand, Iran

3- PhD Student of Health in Disaster and Emergencies, Social Determinants of Health Research Center, Gonabad University of Medical Sciences, Gonabad, Iran

4- Social Determinants of Health Research Center, Gonabad University of Medical Sciences, Gonabad

5- PhD in Health in Disaster and Emergencies, Nursing and Midwifery School, Birjand University of Medical Sciences, Birjand, Iran

6- Assistant Professor, Epidemiology, Social Determinants of Health Research Center, Birjand University of Medical Sciences, Birjand, Iran

Correspondence to: Mohammad Hossein Esmaeilzadeh, Email: esmaeailzadeh.ems@gmail.com
} 
middle-income countries have always revealed higher rates of casualties and damages caused by the varieties of disasters $(2,3)$.

Iran is one of the low-income countries with a high incidence of disasters, accidents, and mass casualties in the world. There is a possibility of earthquakes in more than $90 \%$ of cities and regions of Iran. During the last 97 years, about 40 earthquakes with a magnitude of more than 5 Richter were recorded in the country. According to the Iran Crisis Management Organization (2019), 5,270 natural disasters occurred in the country. Although Iran's population equals only $1 \%$ of the world's population, it accounts for more than $6 \%$ of the world's natural disaster casualties $(3,4)$.

Given the fact that natural disasters affect the health, safety, and well-being of society, the provision of appropriate health services is a factor in the survival, reduction of deaths, and wellbeing of individuals in the aftermath of such events (5). Hospitals are one of the important places to provide health care services in the event of natural disasters and emergencies (6). In addition, preparedness to give an effective response to natural and manmade disasters and provide appropriate health services requires the maintenance and implementation of a well-trained educational program before the occurrence of such events (7).

Since nurses play a vital role in dealing with disasters and accidents and are regarded as the largest group of health care providers and the first service givers in the health system (8), they should be trained professionally to achieve the required preparedness (9). The hospital Preparedness Program before the occurrence of disasters

and emergencies facilitates the transfer and comprehension of the commander's orders. This is due to the fact that order is replaced by chaos and disorder in the event of disasters, and people are less inclined to cooperate as team members to reach a specific goal (6). It should be noted that the mere knowledge about the existence of hazards is not sufficient regarding the use of some preventive behaviors; rather it is the extent and manner of perceiving the risks that result in taking decisions to prevent hazards and be prepared to overcome them (10).

Risk perception refers to the ability to identify and respond to potentially dangerous situations
(11). This concept plays an important role in performing risk prevention behaviors. When people believe that the risk of a disaster is low, they are less likely to take action to reduce it (12-14).

The results of a study conducted by Trsi showed that nurses felt unprepared in response to major crises, which largely depended on their perception of the crisis or their previous experience in this regard (15). Johnson believes that a deep understanding of the risk concept has a positive effect on the quality of services provided by nurses during the crisis (16). Psychometric models and methods are the approaches currently being considered by researchers. One of these models is the Solvic psychometric risk perception theory that includes the examination of the nurse's preparedness, awareness, and emotions during disasters and emergencies (12).

Despite the critical role of nurses and the significance of their presence in responding to disasters and emergencies, few studies have been conducted in this regard (17) emphasizing the gap in crisis nursing and the importance of addressing the issue of education in critical situations (18). In the literature, no study was found on the effect of the implementation of emergency preparedness training programs for nurses in emergencies and disasters on the nurses' risk perception during these events. Therefore, it is necessary to implement a comprehensive educational program as a model that raises the quality of planning and response of nurses in disasters. Accordingly, this study aimed to investigate the effect of educational workshops on disaster risk perception in nurses.

\section{Methods}

This field trial was conducted using a control group. The statistical population consisted of nurses working at Razi Specialty and Subspecialty Hospital in Birjand, Iran. The sample size was estimated at 28 cases for each group based on a similar study conducted by Yousefi et al. (19), the results related to the domains of risk perception before and after the intervention, and the formula for the comparison of the two means. Regarding the sample attrition, the number of the participants in each group increased to 31 cases $(n=62)$. 


$$
\begin{aligned}
\frac{(\mathrm{Z} 1-\alpha / 2+\mathrm{Z} 1-\beta)^{2} \times\left(\mathrm{s}_{1}^{2}+\mathrm{s}_{2}^{2}\right)}{(\bar{x} 1-\bar{x} 2)^{2}} \\
=\frac{(1.96+0.84)^{2} \times\left(9.9^{2}+8.8^{2}\right)}{(37.7-45.4)^{2}}=31
\end{aligned}
$$

The different wards of the hospital were divided into two groups based on the floors on which they were located and the interaction between the wards. Afterward, the nurses were divided into intervention and control groups using non-probability sampling and stratified random allocation methods (Table 1). Eventually, simple random sampling was utilized to assign the nurses of each floor to either the intervention $(n=31)$ or control $(n=31)$ groups.

Before the study, the researcher obtained permission from the Razi Hospital officials to inform the participants about the research objectives and procedures, as well as the confidentiality of their information and the attainment of educational privilege. Afterward, the informed written consent was obtained from the participants. The educational content of the workshop was approved by Continuing Medical Education Center of the Ministry of Health and a permit was issued to hold the workshop. The one-day training workshop was held from 8 am to $4 \mathrm{pm}$ in the hall of Razi Hospital, Birjand, Iran. Before the intervention, the participants were requested to complete the nurses' risk perception questionnaires. Immediately after the workshop and two months later, the nurses were requested to complete the questionnaires again. Data were collected using a researcher-made questionnaire to evaluate the nurses' risk perception during disasters and emergencies based on Solvic's psychometric theory of risk perception including nurse's preparedness, awareness, and emotions. Subsequently, this 18item questionnaire was developed in three domains of preparedness (6 items), awareness (6 items), and emotions (6 items) following the chapters of the National Hospital Preparedness Program (HPP) during disasters and emergencies, including risk and risk assessment, planning, triage, early warning, practice, and risk management.

This questionnaire is rated on a 5-point Likert scale of completely agree $=5$, agree $=4$, no idea $=3$, disagree $=2$, and completely disagree $=1$. Therefore, the scores ranged from 18 to 90 , and higher scores indicated nurses' higher risk perception during disasters and emergencies. The items were designed after reviewing various texts and tools used in similar studies $(10,15,16,20)$. Furthermore, 10 faculty members who were experts in nursing and disaster management were requested to assess the content validity of the questionnaire. Accordingly, it was confirmed in this study. Moreover, the questionnaire was distributed to 10 nurses who were not included in the study to evaluate the reliability. Following that the reliability of the questionnaire was estimated using Cronbach's alpha.

It is worth mentioning that the Cronbach's alpha values of the items evaluating preparedness, emotions, and awareness were estimated at $0.89 \%, 0.61 \%$, and $0.85 \%$, respectively. Subsequently, the intervention group were asked to participate in a one-day $(8 \mathrm{~h})$ training workshop about nurses' preparedness during disasters and emergencies accompanied by lecturing methods $(5 \mathrm{~h})$, practicing (maneuvering around the table), and film display (displaying two films) based on the National HPP program. This standard program was developed based on the modern science by Dr. Khankeh and other experienced professors in the field of disasters and emergencies and approved by the Ministry of Health.

Table 1. Ward Divisions

\begin{tabular}{|cccc}
\hline \multicolumn{2}{c}{ Cardiac wards (first floor of the hospital) } & \multicolumn{2}{c|}{ Other wards (ground floor and second upward) } \\
\multicolumn{2}{c}{ Control group } & \multicolumn{2}{c}{ Intervention group } \\
Wards & Personnel number & Wards & Personnel number \\
Cardiac intensive care 1 & 18 & Emergency & 19 \\
Cardiac intensive care 2 & 12 & Clinic & 7 \\
Internal cardio & 8 & Urology & 10 \\
Angiography & 7 & Operation room & 7 \\
Open heart surgery & 12 & Internal & 13 \\
& & Neurology & 9 \\
\hline
\end{tabular}


The risk perception questionnaire was completed by the nurses participating in the intervention and the control groups in three stages before, immediately after, and two months after the workshop. The "pre-intervention stage" was exactly before the workshop, the "immediately after stage" was the same day of the workshop after the completion of the course, and the "third stage of questionnaire completion" was two months after the completion of the workshop (Figure 1).

The data were analyzed in SPSS software (version 13) (SPSS Inc., Chicago, IL, USA) through descriptive statistics. Moreover, the normal distribution of the data was evaluated using the Kolmogorov-Smirnov test. According to the normal distribution, the data were analyzed using independent t-tests, repeated measures
ANOVA, and Bonferroni post hoc tests. A pvalue less than 0.05 was considered statistically significant.

Regarding the ethical considerations, the study protocol was approved by the Ethics Committee of Birjand University of Medical Sciences, Birjand, Iran (IR.BUMS.REC.1398.037). Subsequently, the educational workshops was performed in the assembly hall of Razi Hospital, Birjand, Iran, after the receipt of the written permit and referral to Razi Hospital, Birjand, Iran. It should be mentioned that the anonymity and confidentiality of the information were respected in this study. The educational content of the workshop was approved by the Continuing Medical Education Center of the Ministry of Health, and the participants in the workshop attained educational privilege. In addition, the

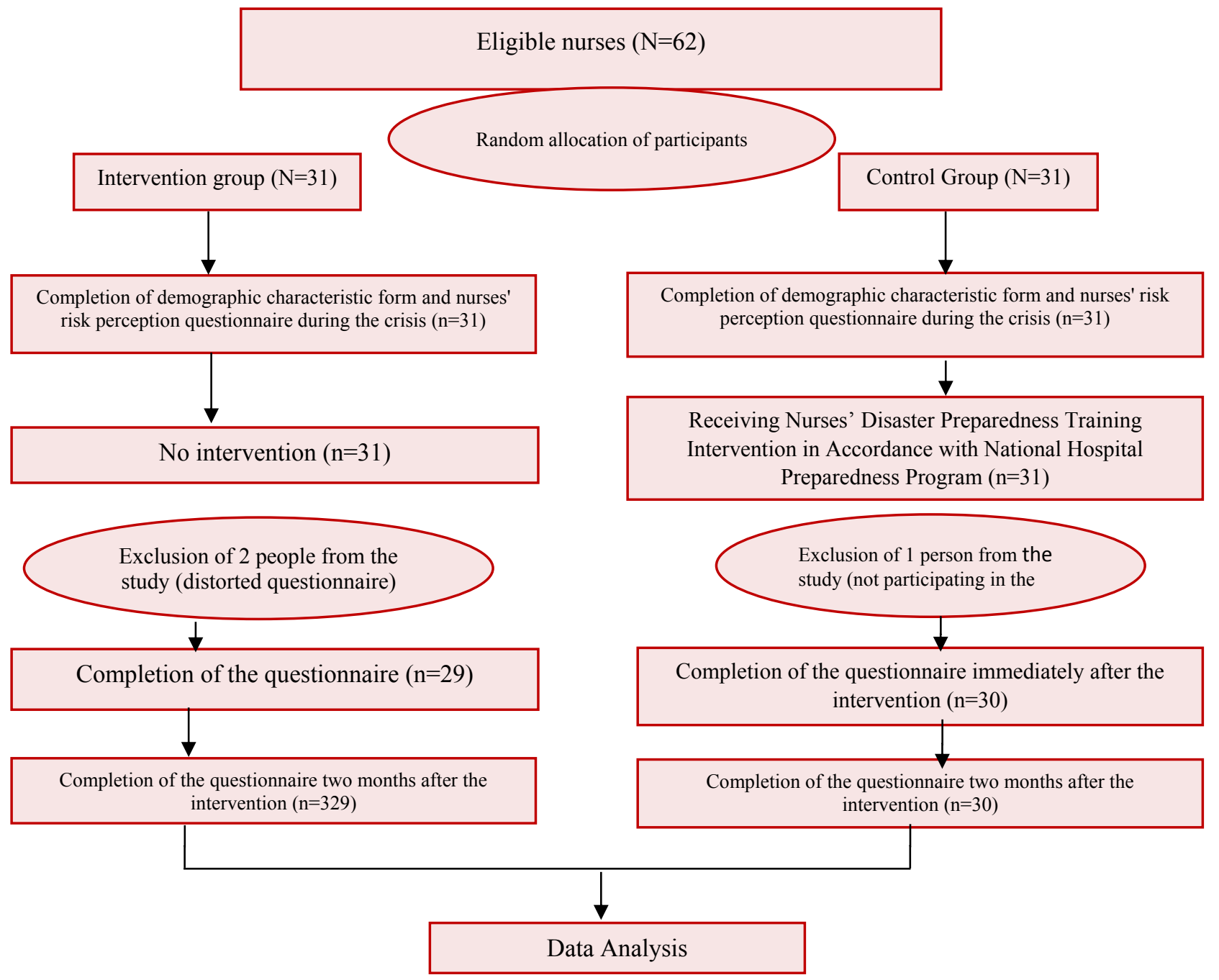

Figure 1. CONSORT flow diagram 
nurses were assured about the optionality of participating in the research and the provision of the results to the research centers.

\section{Findings}

A total of 59 nurses participated in this study. The results of the independent t-test showed no statistically significant difference between the two groups in terms of the mean age and work experience. Furthermore, no statistically significant difference was observed between the two groups regarding other demographic and occupational characteristics based on the Chisquare and Fisher's exact tests. Accordingly, the two groups were homogeneous in this regard ( $>0.05$; Table 2).

The results of the repeated measures ANOVA showed no significant increase in the mean scores of preparedness and emotion as two domains of risk perception in the control group; however, a significant increase was observed in the mean score of awareness and total score of risk perception. According to the results of the Bonferroni post hoc test, a significant increase was found in the mean score of awareness immediately and two months after the intervention, compared to the scores obtained before the intervention. In the same vein, there was a significant increase in the total score of risk perception two months after the intervention, compared to the scores before the intervention (Table 3).

The results of the comparison of mean score variations indicated a significant increase in the

Table 2. Comparison of the two intervention and control groups regarding the demographic characteristics

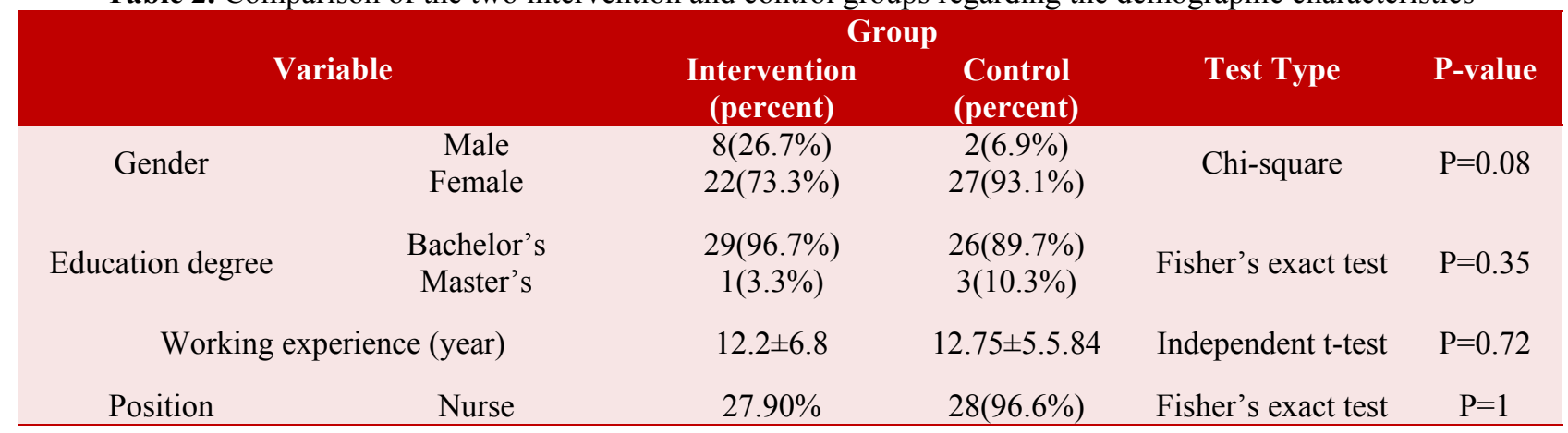

Table 3. Comparison of the intervention and control groups regarding preparedness, emotion, and awareness scores before, immediately, and two months after the intervention

\begin{tabular}{|c|c|c|c|c|c|c|c|c|}
\hline \multirow[b]{2}{*}{ Groups } & \multirow[b]{2}{*}{ Domain } & \multirow[b]{2}{*}{$\begin{array}{l}\text { Before the } \\
\text { intervention }\end{array}$} & \multicolumn{3}{|l|}{ Time } & \multicolumn{3}{|c|}{ Significance level of Bonferroni test } \\
\hline & & & $\begin{array}{l}\text { Immediately } \\
\text { after the } \\
\text { intervention }\end{array}$ & $\begin{array}{l}\text { Two months } \\
\text { after the } \\
\text { intervention }\end{array}$ & $\begin{array}{l}\text { Result of the } \\
\text { repeated } \\
\text { measures } \\
\text { ANOVA }\end{array}$ & $\begin{array}{l}\text { The scores } \\
\text { before the } \\
\text { intervention, } \\
\text { compared to } \\
\text { those } \\
\text { immediately } \\
\text { after the } \\
\text { intervention }\end{array}$ & $\begin{array}{l}\text { The scores } \\
\text { before the } \\
\text { intervention, } \\
\text { compared to } \\
\text { those two } \\
\text { months after } \\
\text { the } \\
\text { intervention }\end{array}$ & $\begin{array}{l}\text { The scores } \\
\text { immediately } \\
\text { after the } \\
\text { intervention, } \\
\text { compared to } \\
\text { those two } \\
\text { months after the } \\
\text { intervention }\end{array}$ \\
\hline \multirow{4}{*}{ 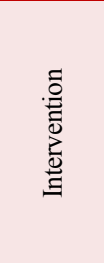 } & $\begin{array}{l}\text { Risk perception } \\
\text { preparedness }\end{array}$ & $22.7 \pm 4$ & $24.8 \pm 3.4$ & $27.4 \pm 2.3$ & $\mathrm{P}<0.001$ & 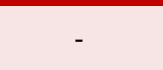 & $\mathrm{P}<0.05$ & $\mathrm{P}<0.001$ \\
\hline & $\begin{array}{l}\text { Risk perception } \\
\text { emotions }\end{array}$ & $26 \pm 3.1$ & $24.9 \pm 3.9$ & $27.96 \pm 2$ & $\mathrm{P}<0.001$ & - & $\mathrm{P}=0.001$ & $\mathrm{P}<0.001$ \\
\hline & $\begin{array}{l}\text { Risk perception } \\
\text { awareness }\end{array}$ & $22.5 \pm 5$ & $24.5 \pm 3.4$ & $28.2 \pm 2$ & $\mathrm{P}<0.001$ & - & $\mathrm{P}<0.001$ & $\mathrm{P}<0.001$ \\
\hline & $\begin{array}{l}\text { Total score of risk } \\
\text { perception }\end{array}$ & $71.2 \pm 10.3$ & $74.2 \pm 10$ & $83.7 \pm 4.9$ & $\mathrm{P}<0.001$ & - & - & $\mathrm{P}<0.001$ \\
\hline \multirow{4}{*}{ 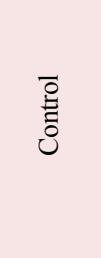 } & $\begin{array}{l}\text { Risk perception } \\
\text { preparedness }\end{array}$ & $21.2 \pm 3.9$ & $22 \pm 4$ & $22.4 \pm 4.5$ & $\mathrm{P}=0.2$ & - & - & - \\
\hline & $\begin{array}{l}\text { Risk perception } \\
\text { emotions }\end{array}$ & $23.4 \pm 3.4$ & $23.9 \pm 3.5$ & $23.8 \pm 3.2$ & $\mathrm{P}=0.74$ & - & - & - \\
\hline & $\begin{array}{l}\text { Risk perception } \\
\text { awareness }\end{array}$ & $21.11 \pm 4.4$ & $23.5 \pm 3.4$ & $22.8 \pm 4.5$ & $\mathrm{P}<0.001$ & $\mathrm{P}<0.05$ & $\mathrm{P}<0.05$ & - \\
\hline & $\begin{array}{l}\text { Total score of Risk } \\
\text { Perception }\end{array}$ & $56.8 \pm 9.9$ & $69.4 \pm 9.21$ & $69 \pm 10.4$ & $\mathrm{P}=0.05$ & - & $\mathrm{P}<0.05$ & - \\
\hline
\end{tabular}


Table 4. Comparison of the two intervention and control groups regarding the mean score variations in three risk perception domains of preparedness, emotions, and awareness, before, immediately, and two months after the educational workshop

\begin{tabular}{|c|c|c|c|c|}
\hline \multirow{2}{*}{ Domain } & \multirow{2}{*}{ Time } & \multicolumn{2}{|c|}{ Groups } & \multirow{2}{*}{$\begin{array}{c}\text { P-value } \\
\text { Independent t-test }\end{array}$} \\
\hline & & Intervention & Control & \\
\hline \multirow{3}{*}{$\begin{array}{l}\text { Score variation of risk } \\
\text { perception preparedness }\end{array}$} & $\begin{array}{c}\text { Before and immediately after the } \\
\text { intervention }\end{array}$ & $4.78 \pm 2$ & $0.75 \pm 3.6$ & $\mathrm{P}=0.24$ \\
\hline & $\begin{array}{l}\text { Before and two months after the } \\
\text { intervention }\end{array}$ & $4.86 \pm 4$ & $2.25 \pm 1.17$ & $\mathrm{P}=0.001$ \\
\hline & $\begin{array}{l}\text { Immediately and two months after } \\
\text { the intervention }\end{array}$ & $2.73 \pm 2.21$ & $0.41 \pm 4.39$ & $\mathrm{P}=0.01$ \\
\hline \multirow{3}{*}{$\begin{array}{l}\text { Score variation of risk } \\
\text { perception emotion }\end{array}$} & $\begin{array}{c}\text { Before and immediately after the } \\
\text { intervention }\end{array}$ & $4.86 \pm 1.10$ & $3.67 \pm 0.44$ & $\mathrm{P}=0.17$ \\
\hline & $\begin{array}{l}\text { Before and two months after the } \\
\text { intervention }\end{array}$ & $3.56 \pm 1.93$ & $2.47 \pm 0.41$ & $\mathrm{P}=0.06$ \\
\hline & $\begin{array}{l}\text { Immediately and two months after } \\
\text { the intervention }\end{array}$ & $3.03 \pm 3.07$ & $3.95 \pm 0.03$ & $\mathrm{P}=0.02$ \\
\hline \multirow{3}{*}{$\begin{array}{l}\text { Score variation of risk } \\
\text { perception awareness }\end{array}$} & $\begin{array}{l}\text { Before and immediately after the } \\
\text { intervention }\end{array}$ & $6.3 \pm 2.0$ & $2.37 \pm 3.62$ & $\mathrm{P}=0.77$ \\
\hline & $\begin{array}{l}\text { Before and two months after the } \\
\text { intervention }\end{array}$ & $5.73 \pm 5.27$ & $1.56 \pm 3.01$ & $\mathrm{P}=0.001$ \\
\hline & $\begin{array}{l}\text { Immediately and two months after } \\
\text { the intervention }\end{array}$ & $3.73 \pm 2.8$ & $0.72 \pm 4.5$ & $\mathrm{P}=0.001$ \\
\hline \multirow{3}{*}{$\begin{array}{l}\text { Total score of risk } \\
\text { perception }\end{array}$} & $\begin{array}{c}\text { Before and immediately after the } \\
\text { intervention }\end{array}$ & $14.1 \pm 2.96$ & $3.58 \pm 8.64$ & $\mathrm{P}=0.84$ \\
\hline & $\begin{array}{l}\text { Before and two months after the } \\
\text { intervention }\end{array}$ & $12.46 \pm 10.1$ & $3.24 \pm 6.11$ & $\mathrm{P}=0.001$ \\
\hline & $\begin{array}{l}\text { Immediately and two months after } \\
\text { the intervention }\end{array}$ & $9.5 \pm 6.98$ & $10.1 \pm 0.34$ & $\mathrm{P}=0.001$ \\
\hline
\end{tabular}

scores of all three domains of awareness, preparedness, and emotions, as well as the total score of risk perception in the intervention group before, immediately, and two months after training, compared to the control group (Table 4). Similarly, the results of the Bonferroni post hoc test showed that the intervention group obtained a higher increase in the mean scores of awareness, preparedness, and emotions, as well as the total score of the nurses' risk perception two months after the intervention, compared to the scores obtained immediately after the intervention $(\mathrm{P}<0.001)$.

\section{Discussion and Conclusion}

This study aimed to determine the effect of the implementation of the National HPP during disasters and emergencies on the nurses' risk perception. The intervention group obtained higher mean score variations of awareness, preparedness, and emotions, as well as the total score of the risk perception before, immediately, and two months after the intervention, compared to the control group $(\mathrm{P}<0.001)$. This indicates a significant relationship between the implementtation of National HPP during disasters and emergencies and the enhancement of nurse's risk perception. Based on the results of this study, the National HPP during disasters and emergencies improved the nurses' risk perception scores two months after the intervention, compared to the scores obtained before and immediately after the intervention. According to a study conducted by Samadipour et al., the implementation of comprehensive programs can improve general health and increase preparedness during critical 
situations (21). There was a significant difference between the intervention and control groups regarding risk perception immediately and two months after the intervention. Furthermore, the intervention group obtained a higher total score of risk perception two months after the intervention, compared to the scores before the educational workshop. It should be mentioned that this difference was also found between the scores obtained immediately after and two months after the workshop.

Risk awareness is one of the domains of risk perception. The results showed that the mean score of risk perception awareness was significant in the intervention group in the pre-intervention stage compared to that in two-month postintervention stage as well as in the immediately post-intervention stage, compared to that in twomonth post-intervention stage.

Saeedi Mehr et al. in 2015 showed a significant difference between the scores obtained before versus after the intervention in terms of the nurses' awareness level in face of crisis and the way to deal with it. Accordingly, crisis management training has been effective in the nurses' awareness to manage critical conditions; however, there was no factor to measure the risk perception awareness specifically (4). Emotion is the other domain of risk perception, and the results showed a significant difference between the mean risk perception emotion scores obtained before and those taken after the workshop in the intervention group. This difference was also observed between the scores obtained immediately and after the workshop. According to a study conducted by Ahmadi in 2014, the risk perception is affected by the people's feelings about their knowledge, control over the situation, as well as familiarity with the incident and its severity. When nurses feel that they have control over the situation, hazardous and destructive incidents can be felt less than what they are (22).

The results of a study evaluating risk management in the health and treatment system in Italy indicated various approaches to risk management due to different cultural issues. Moreover, the findings revealed that the risk perception culture should be implemented through risk management education. In addition, the results confirmed the effectiveness of the risk management educations (23), which was consistent with the findings of the present study.
In the same line, Weber et al. indicated a significant improvement in the nurses' self-confidence and preparedness after the implementation of practical education to prepare the nurses for mass casualties based on the nursing theory of Kurt Levine (16). Increased self-confidence and trusts in managers were among the factors affecting the risk perception emotions, the role of which has been well affirmed in the aforementioned studies. However, the self-confidence and trust levels have not been measured so far, which is one of the differences between the current study and the other studies in this regard.

The other domain of risk perception is risk preparedness. The results indicated that the intervention group obtained a higher total score of risk preparedness two months after the intervention, compared to the scores before the educational workshop. It should be mentioned that this difference was also found between the scores obtained immediately after and two months after the workshop. The results of a study conducted by Tabibi et al. in 2016 showed that nurses who participated in scenario-based desk exercises were better prepared and had higher self-confidence levels when confronting natural disasters and emergencies (24). Similarly, according to a study conducted by Imani et al. in 2011, a relationship was observed between an increase in the awareness and preparedness of the participants and their participation in the round-table exercise of crisis management as well as membership in the crisis committee (25). The findings of these studies are in line with those of the present study.

The results of a study conducted by Trsi et al. in Canada during 2019 showed that nurses felt unprepared to encounter large-scale crises. This feeling largely depends on their perception of the crisis or their previous experience of encountering the crisis. They also reported the poor preparedness level of Canadian health care centers in dealing with the crisis (15). However, the risk perception level during disasters and emergencies was not evaluated in this study. Accordingly, it was not possible to determine the consistency and inconsistency between the results of the present study and the aforementioned study.

It should be noted that the results of the present study were in line with the findings of the aforementioned study regarding the statistical population and some factors in the data collection 
tools. Nonetheless, it was not possible to determine the consistency and inconsistency between the results of the present study and the aforementioned study. Therefore, no similar studies were found to assess the nurses' risk perception during disasters and emergencies using similar data collection tools.

Regarding the limitations of the present study, one can refer to a dearth of research investigating nurses' risk perception awareness during disasters and emergencies, which led to some restrictions in comparisons and results. However, attempts have been made to overcome this limitation by utilizing studies conducted in other areas. The results of the present study indicated the positive impact of the implementation of a one-day education preparedness workshop on the nurses' risk perception during emergencies and disasters.

Therefore, the National Preparedness Program during disasters and emergencies can be integrated into the training program of the nurses at hospitals. Moreover, it can be employed as a codified in-service retraining program to improve their participation in disasters and emergencies by increasing their risk perception levels during these events. Given the importance of nurses' risk perception during disasters and emergencies, the possession of risk perception to some extent can be considered a requirement for the nurses' recruitment, which can be evaluated in further studies.

\section{Acknowledgments}

The present study was extracted from an MSc thesis in Emergency Nursing (IR.BUMS.REC. 1398.037). The author(s) would like to express their gratitude to the manager and nurses in the Office of Nursing, as well as the esteemed professors and experts in disasters and emergencies at Birjand University of Medical Sciences, Birjand, Iran.

\section{Conflict of Interests}

Authors have no conflict of interests.

\section{References}

1. Nivolianitou Z, Synodinou B. Towards emergency management of natural disasters and critical accidents: the Greek experience. J Environ Manage 2011; 92(10): 2657-65.

2. Boustan LP, Kahn ME, Rhode PW, Yanguas ML.
The effect of natural disasters on economic activity in US counties: a century of data. J Urban Econ 2020; 118: 103257.

3. Ghomian Z, Yousefian S. Natural disasters in the middle-east and North Africa with a focus on Iran: 1900 to 2015. Health Emerg Disasters 2017; 2(2): 53-62.

4. Mokhtari Hashi HM, Rahimi D. Zoning of flood risk in human and economic activities centers of South Khorasan Province using the fuzzy logic system. Geography Environ Plan 2016; 27(1): 199-216.

5. Jourvand R, Sadeghirad K, Golami OA, Vejdani M, Panahi R, Heydarabadi AB. Disasters preparedness of health workers in Dehloran, Iran. J Health Field 2015; 3(3): 13-8.

6. Khankeh HR, Masumi G. National hospital disaster risk management program based on accreditation incident. Tehran: Ministries Ministry of Health, Treatment and Medical Training; 2017.

7. Chapman K, Arbon P. Are nurses ready? Disaster preparedness in the acute setting. Austral Emerg Nurs J 2008; 11(3): 135-44.

8. Pourvakhshoori N, Norouzi K, Ahmadi F, Hosseini M, Khankeh H. Nursing in disasters: a review of existing models. Int Emerg Nurs 2017; 31: 58-63.

9. Diab GM, Mabrouk SM. The effect of guidance booklet on knowledge and attitudes of nurses regarding disaster preparedness at hospitals. J Nurs Educ Pract 2015; 5(9): 17-31.

10. Asgarizadeh Z, Rafieian M, Dadashpoor H. The role of risk perception on risk mitigation behaviors (case study: earthquake in Tehran). J Emerg Manag 2018; 6(2): 57-68.

11. Khankeh HR. Hospital preparedness in emergencies and disasters. Tehran: University of Social Welfare and Rehabilitation Sciences; 2012.

12. Cutter SL, Barnes L, Berry M, Burton C, Evans $\mathrm{E}$, Tate E, et al. A place-based model for understanding community resilience to natural disasters. Global Environ Change 2008; 18(4): 598-606.

13. Slovic P, Fischhoff B, Lichtenstein S. Why study risk perception? Risk Analysis 1982; 2(2): 83-93.

14. McCaffrey S. Thinking of wildfire as a natural hazard. Soc Nat Res 2004; 17(6): 509-16.

15. O'Sullivan TL, Dow D, Turner MC, Lemyre L, Corneil W, Krewski D, et al. Disaster and emergency management: Canadian nurses' perceptions of preparedness on hospital front lines. Prehospital Disaster Med 2008; 23(S1): S11-9.

16. Weber NM. When disaster strikes: a training intervention to improve nurses' confidence and preparedness for the surge. Valparaiso, Indiana: Valparaiso University; 2018.

17. Bahrami M, Aliakbari F, Aein F. Iranian nurses' perception of essential competences in disaster response: a qualitative study. J Educ Health Promot 
2014; 3: 81 .

18. Xia SS, Yang BX, Chen XL, Petrini MA, Schory SA, Liu Q. Application and effects of a disaster nursing simulation training for Chinese undergraduates. J Nurs Educ Pract 2016; 6(10): 8-15.

19. Yousefi S, Khankeh H, Akbari Y, Dalvandi A, Bakhshi E. The effect of the implementation of the national program for hospital preparedness on the readiness of nurses under simulated conditions of incidents and disasters. Health Emerg Disasters Qurt 2016; 2(1): 39-43.

20. Zhang J, While AE, Norman IJ. Development and testing of an instrument to assess nurses' knowledge, risk perception, health beliefs and behaviours related to influenza vaccination. J Clin Nurs 2012; 21(17-18): 2636-46.

21. Samamdipour E, Seyedin H, Ravaghi H. Roles, responsibilities, and strategies for enhancing disaster risk perception: a quantitative study. J Educ Health Promot 2019; 8: 9.

22. Ahmadi $M$. The role of nurses in bioterrorism incidents. 6th International Congress on Health in Emergencies and Disasters, Tehran, Iran; 2014.

23. Verbano C, Turra F. A human factors and reliability approach to clinical risk management: evidence from Italian cases. Saf Sci 2010; 48(5): 625-39.

24. Tabiee S, Nakhaee M. Nurses' preparedness for disaster in South Khorasan Province, Iran. Health Emerg Disasters Quart 2016; 2(1): 13-8.

25. Iman E, Hosseini Teshnizi S, Tafrihi M, Alavi A, Jafari A, Badri S, et al. Nurses knowledge about crisis management and its related factors. J Health Care 2011; 13(4): 10-8. 